\title{
Clinical Characteristics of Hospitalized Patients with SARS-CoV-2 and Hepatitis B Virus Co-infection
}

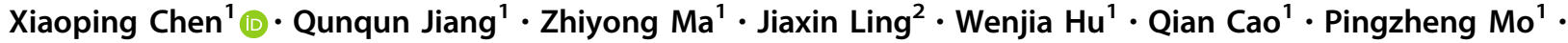

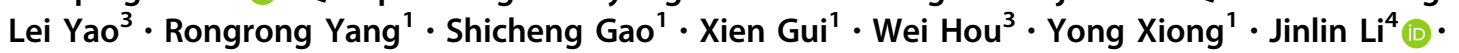 \\ Yongxi Zhang' ${ }^{1}$
}

Received: 17 May 2020 / Accepted: 13 July 2020 / Published online: 24 August 2020

(c) Wuhan Institute of Virology, CAS 2020

\section{Dear Editor,}

Coronavirus disease 2019 (COVID-19) is a global pandemic caused by severe acute respiratory syndrome coronavirus 2 (SARS-CoV-2). SARS-CoV-2 infection was first detected in Wuhan, China in late December 2019. The virus was spreading rapidly to other cities of China and accumulating cases had been reported (Li et al. 2020). On March 11, 2020, WHO declared the outbreak of SARSCoV-2 as a pandemic. As of June 28, around 10 million COVID-19 cases have been reported in 216 countries or territories and the worldwide death toll has passed 490,000 according to data from WHO (https://www.who.int/emer gencies/diseases/novel-coronavirus-2019). Until now, there is no effective drug or vaccine available against SARSCov-2 infection.

In addition to the recent emerged SARS-CoV-2, hepatitis $\mathrm{B}$ virus (HBV) is one of the viruses which cause a

Xiaoping Chen, Qunqun Jiang and Zhiyong Ma contributed equally to this work.

Electronic supplementary material The online version of this article (https://doi.org/10.1007/s12250-020-00276-5) contains supplementary material, which is available to authorized users.

Yongxi Zhang

znact1936@126.com

$\bowtie$ Jinlin Li

jinlinli@whu.edu.cn

$\triangle$ Xiaoping Chen

alackcn@126.com

1 Department of Infectious Diseases, Zhongnan Hospital of Wuhan University, Wuhan 430071, China

2 Department of Medical Biochemistry and Microbiology, Zoonosis Science Center, University of Uppsala,

75123 Uppsala, Sweden global infection and threat public health. In worldwide, the prevalence of HBsAg is about 3.9\% (Polaris Observatory 2018). According to a nationwide epidemiological survey of population whose ages range from 1 to 59 years in China, 2006, the prevalence of HBsAg was 7.2\% (Liang et al. 2009). As SARS-CoV-2 and HBV both can cause liver damage (Fan et al. 2020), further understanding of the risk of SARS-CoV-2 on patients with HBV infection is urgently required in order to design an optimized treatment strategy. However, the impacts of SARS-CoV-2 infection on HBV patients are still not clear. For example, we do not yet know whether the SARS-CoV-2 infection is more severe in HBV patients and we also do not have much knowledge about the impact of SARS-CoV-2 on the course of HBV infection. In this retrospective study, we investigated the clinical characterizes of the patients coinfected with SARS-CoV-2 and HBV by analyzing the clinical records and laboratory tests of 123 COVID-19 patients admitted to Zhongnan Hospital of Wuhan University, Wuhan, China, from January 5 to February 20, 2020.

A total of 123 patients with COVID-19 were enrolled in this study, including 50 males and 73 females. The median age of total enrolled patients was 51.0 years (IQR, 35.0-66.0; range, 20-96 years). The most common

3 State Key Laboratory of Virology/Institute of Medical Virology/Hubei Province Key Laboratory of Allergy and Immunology, School of Basic Medical Sciences, Wuhan University, Wuhan 430071, China

4 Department of Cell and Molecular Biology, Karolinska Institute, 17165 Stockholm, Sweden 
Table 1 Demographics, baseline characteristics, laboratory results, treatment and clinical outcomes of 123 COVID-19 patients with or without HBV infection.

$\begin{array}{lll}\text { Total }(\mathrm{n}=123) & \text { With HBV infection } & \begin{array}{l}\text { Without HBV infection } \\ (\mathrm{n}=108)\end{array}\end{array}$

\begin{tabular}{|c|c|c|c|c|}
\hline Sex & & & & 0.0469 \\
\hline Female & $73(59.3 \%)$ & $5(33.3 \%)$ & $68(63.0 \%)$ & \\
\hline Male & $50(40.7 \%)$ & $10(66.7 \%)$ & $40(37.0 \%)$ & \\
\hline Age, median (IQR), y & $51.0(35.0,66.0)$ & $54.0(39.0,60.0)$ & $51.0(35.0,66.0)$ & 0.6127 \\
\hline Comorbidities & $35(28.5 \%)$ & $4(26.7 \%)$ & $31(28.7 \%)$ & 1.0000 \\
\hline Hypertension & $19(15.4 \%)$ & $1(6.7 \%)$ & $18(16.7 \%)$ & 0.4628 \\
\hline Cardiovascular disease & $8(6.5 \%)$ & $0(0.0 \%)$ & $8(7.4 \%)$ & 0.5939 \\
\hline Diabetes & $12(9.8 \%)$ & $1(6.7 \%)$ & $11(10.2 \%)$ & 1.0000 \\
\hline Malignancy & $5(4.1 \%)$ & $3(20.0 \%)$ & $2(1.9 \%)$ & 0.0724 \\
\hline COPD & $5(4.1 \%)$ & $0(0.0 \%)$ & $5(4.6 \%)$ & 1.0000 \\
\hline Liver cirrhosis & $3(2.4 \%)$ & $2(13.3 \%)$ & $1(0.9 \%)$ & 0.0390 \\
\hline \multicolumn{5}{|l|}{ Signs and symptoms } \\
\hline Fever & $85(69.1 \%)$ & $8(53.3 \%)$ & $77(71.3 \%)$ & 0.2310 \\
\hline Fatigue & $67(54.5 \%)$ & $8(53.3 \%)$ & $59(54.6 \%)$ & 1.0000 \\
\hline Myalgia & $40(32.5 \%)$ & $3(20.0 \%)$ & $37(34.3 \%)$ & 0.7604 \\
\hline Cough & $62(50.4 \%)$ & $4(26.7 \%)$ & $58(53.7 \%)$ & 0.0582 \\
\hline Dyspnea & $26(21.1 \%)$ & $6(40.0 \%)$ & $20(18.5 \%)$ & 0.0859 \\
\hline Diarrhea & $20(16.3 \%)$ & $2(13.3 \%)$ & $18(16.7 \%)$ & 1.0000 \\
\hline Headache & $21(17.1 \%)$ & $2(13.3 \%)$ & $19(17.6 \%)$ & 1.0000 \\
\hline Days from illness onset to hospital, median (IQR), d & $7.0(4.0,10.0)$ & $7.0(4.0,10.0)$ & $7.0(4.0,10.0)$ & 0.9102 \\
\hline \multicolumn{5}{|l|}{ Laboratory results (units, normal range) } \\
\hline White blood cell Count $\left(\times 10^{9} / \mathrm{L}, 3.5-9.5\right)$ & $4.2(3.0,5.7)$ & $4.4(3.4,5.6)$ & $4.2(2.9,5.7)$ & 0.6484 \\
\hline Lymphocyte count $\left(\times 10^{9} / \mathrm{L}, 1.1-3.2\right)$ & $0.9(0.6,1.3) \downarrow$ & $0.6(0.4,1.1) \downarrow$ & $0.9(0.6,1.3) \downarrow$ & 0.0598 \\
\hline Neutrophil count $\left(\times 10^{9} / \mathrm{L}, 1.8-6.3\right)$ & $2.5(1.6,3.8)$ & $3.4(2.3,5.3)$ & $2.5(1.6,3.7)$ & 0.2091 \\
\hline Platelet count $\left(\times 10^{9} / \mathrm{L}, 125-350\right)$ & $179.0(129.0,2250)$ & $186.0(104.0,225.0)$ & $178.5(130.3,225.5)$ & 0.7020 \\
\hline Alanine aminotransferase (ALT) (U/L, 9-50) & $22.0(15.0,34.5)$ & $25.0(16.0,44.0)$ & $21.5(15.0,32.8)$ & 0.4418 \\
\hline Aspartate aminotransferase (AST) (U/L, 15-40) & $25.0(19.0,38.0)$ & $28.0(19.0,58.0)$ & $25.0(19.0,37.0)$ & 0.6327 \\
\hline Total bilirubin (TBIL) (mmol/L, 5-21) & $9.6(7.8,12.8)$ & $13.2(10.0,17.4)$ & $9.4(7.6,12.3)$ & 0.0178 \\
\hline Gamma-glutamyltransferase (GGT) (U/L, 8-57) & $22.0(15.0,36.0)$ & $20.0(14.0,28.0)$ & $22.0(15.3,36.8)$ & 0.5110 \\
\hline Alkaline phosphatase (ALP) (U/L, 30-120) & $66.0(54.0,83.0)$ & $76.0(52.0,102.0)$ & $65.0(54.0,79.8)$ & 0.2339 \\
\hline Albumin $(\mathrm{g} / \mathrm{L}, 40-55)$ & $38.2(34.4,41.0) \downarrow$ & $36.0(30.9,39.6) \downarrow$ & $38.3(34.6,41.1) \downarrow$ & 0.2309 \\
\hline Prothrombin time (s, 9.4-12.5) & $12.7(11.7,13.3) \uparrow$ & $13.0(11.5,13.9) \uparrow$ & $12.7(11.8,13.3) \uparrow$ & 0.2376 \\
\hline Activated partial thromboplastin time (s, 25.1-36.5) & $30.7(28.5,32.6)$ & $30.6(27.9,32.7)$ & $30.9(28.6,32.6)$ & 0.4557 \\
\hline International normalized ratio $(0.85-1.15)$ & $1.2(1.1,1.2) \uparrow$ & $1.2(1.1,1.3) \uparrow$ & $1.2(1.1,1.2) \uparrow$ & 0.2324 \\
\hline D-dimer (mg/L, 0-500) & $204.0(126.0,464.0)$ & $270.0(101.0,2139.0)$ & $195.5(128.0,438.8)$ & 0.4794 \\
\hline Creatinine $(\mu \mathrm{mol} / \mathrm{L}, 64-104)$ & $62.9(52.6,76.9) \downarrow$ & $65.4(59.0,81.1)$ & $61.9(52.4,73.5) \downarrow$ & 0.2177 \\
\hline Severe type & $33(26.8 \%)$ & $7(46.7 \%)$ & $26(24.1 \%)$ & 0.1152 \\
\hline \multicolumn{5}{|l|}{ Treatment } \\
\hline Oxygen support & $74(60.2 \%)$ & $8(53.3 \%)$ & $66(61.1 \%)$ & 0.5842 \\
\hline Antiviral therapy & $90(73.2 \%)$ & $8(53.3 \%)$ & $82(75.9 \%)$ & 0.1152 \\
\hline Antibiotic therapy & $123(100.0 \%)$ & $15(100.0 \%)$ & $108(100.0 \%)$ & - \\
\hline Use of corticosteroid & $61(49.6 \%)$ & $5(33.3 \%)$ & $56(51.9 \%)$ & 0.2704 \\
\hline Hospital stays, median (IQR), days & $14.0(9.0,20.0)$ & $14.0(11.0,18.0)$ & $14.0(9.0,21.0)$ & 0.9383 \\
\hline \multicolumn{5}{|l|}{ Clinical outcome } \\
\hline Remained in hospital & $8(6.5 \%)$ & $2(13.3 \%)$ & $6(5.6 \%)$ & 0.0690 \\
\hline Discharged & $110(89.4 \%)$ & $11(73.4 \%)$ & $99(91.6 \%)$ & \\
\hline Death & $5(4.1 \%)$ & $2(13.3 \%)$ & $3(2.8 \%)$ & \\
\hline
\end{tabular}

Bold represents the significant difference of $P$ values less than 0.05

The arrow $\downarrow$ : decrease; $\uparrow$ : increase 
symptoms at the onset of illness were: fever $\left(37.4-39.1^{\circ} \mathrm{C}\right.$, $69.1 \%$ ), fatigue $(54.5 \%)$, cough $(50.4 \%)$, and myalgia $(32.5 \%)$ (Table 1). Other symptoms included dyspnea $(21.1 \%)$, headache $(17.1 \%)$ and diarrhea $(16.3 \%)$. Among 123 enrolled patients, thirty-five $(28.5 \%)$ cases had at least one underlying comorbidity such as hypertension, cardiovascular disease, diabetes, malignancy, COPD or liver cirrhosis. Around $12.2 \%(15 / 123)$ of patients were also suffering from $\mathrm{HBV}$ infection. There were more males than females (10:5) co-infected with HBV and SARS-CoV-2 $(P=0.0469$, Table 1). The treatment for COVID-19 patients was mainly supportive. Ninety patients were given the antiviral (oral arbidol and/or lopinavir). Seventy-four patients were offered with oxygen support and antibiotic therapy (both orally and intravenous). Sixty-one patients received corticosteroids to suppress an excessive inflammatory activation. There is no significant difference of treatments between patients with and without HBV infection (Table 1).

Laboratory results indicated that the level of total bilirubin was higher in patients with $\mathrm{HBV}$ infection ( $P=0.0178$, Table 1$)$. The blood counts of the patients with or without $\mathrm{HBV}$ infection showed lymphopenia $\left(<1.3 \times 10^{9} / \mathrm{L}\right.$, Table 1$)$. Fifteen COVID-19 patients were examined to be HBsAg positive ( 5 females and 10 males). The data of anti-HBsAg, $\mathrm{HBeAg}$, anti-HBeAg and anti$\mathrm{HBcAg}$ were available for 11 patients with $10 \mathrm{HBeAg}$ negative and one positive. HBV-DNA was detected in 13 patients. The HBV-DNA level of 10 patients was more than $20 \mathrm{IU} / \mathrm{mL}$. Among the 15 patients, two patients have cirrhosis; three patients were treated with nucleoside analogue (oral entecavir, $0.5 \mathrm{mg}$, once daily) during the retrospective investigation period (Table 2).

Among 15 COVID-19 patients with HBV infection, 11 patients $(73.4 \%)$ were discharged from the hospital according to the guideline; two patients $(13.3 \%)$ were still hospitalized and the other two patients (13.3\%) were dead. The causes of death are upper gastrointestinal bleeding and Intestinal bleeding respectively (Supplementary Table S1). In the group of 108 COVID-19 patients without HBV infection, ninety-nine patients $(91.6 \%)$ were discharged from hospital while 6 patients $(5.6 \%)$ were still hospitalized. Three patients $(2.8 \%)$ without HBV infection were dead due to respiratory failure (Table 1, Supplementary Table S1). The detailed information of five dead patients was shown in Supplementary Table S1.

In line with previous observations (Chen et al. 2020; Guan et al. 2020; Huang et al. 2020; Shi et al. 2020; Wang et al. 2020; Xu et al. 2020; Yang et al. 2020; Zhang et al. 2020), we found that in COVID-19 cases without HBV infection about $50.9 \%$ (55/108) patients have the dysfunction of liver symptoms by measuring the level of ALT, AST, TBIL, GGT, and ALP during the disease progress.

Furthermore, we uncovered patients with HBV infection had a higher rate of liver cirrhosis $(P=0.0390$, Table 1$)$. Seven of 15 patients $(46.7 \%)$ with $\mathrm{HBV}$ infection

Table 2 Hepatitis B serological markers, cirrhosis and nucleoside analogue use of COVID-19 patients co-infected with HBV.

\begin{tabular}{|c|c|c|c|c|c|c|c|c|c|c|}
\hline Patient & $\begin{array}{l}\text { Age } \\
\text { (years) }\end{array}$ & $\begin{array}{l}\text { Sex } \\
\text { (female/male) }\end{array}$ & $\begin{array}{l}\text { HBsAg } \\
\text { (Pos/ } \\
\text { Neg) }\end{array}$ & $\begin{array}{l}\text { Anti- } \\
\text { HBs } \\
\text { (Pos/ } \\
\text { Neg) }\end{array}$ & $\begin{array}{l}\mathrm{HBeAg} \\
\text { (Pos/ } \\
\mathrm{Neg})\end{array}$ & $\begin{array}{l}\text { Anti- } \\
\mathrm{HBe} \\
\text { (Pos/ } \\
\mathrm{Neg} \text { ) }\end{array}$ & $\begin{array}{l}\text { Anti- } \\
\mathrm{HBc} \\
\text { (Pos/ } \\
\mathrm{Neg})\end{array}$ & $\begin{array}{l}\mathrm{HBV}- \\
\text { DNA } \\
\text { (IU/ } \\
\mathrm{mL},<20 \text { ) }\end{array}$ & Cirrhosis & $\begin{array}{l}\text { Use of nucleoside } \\
\text { analogue }\end{array}$ \\
\hline 1 & 38 & Male & Pos & NA & NA & NA & NA & 100.0 & & \\
\hline 2 & 54 & Male & Pos & NA & NA & NA & NA & NA & & \\
\hline 3 & 74 & Male & Pos & $\mathrm{Neg}$ & $\mathrm{Neg}$ & Pos & Pos & $<20$ & Yes & Yes \\
\hline 4 & 36 & Female & Pos & $\mathrm{Neg}$ & $\mathrm{Neg}$ & $\mathrm{Neg}$ & Pos & 211.0 & & \\
\hline 5 & 48 & Male & Pos & $\mathrm{Neg}$ & Neg & Pos & Pos & 235.0 & & \\
\hline 6 & 60 & Male & Pos & $\mathrm{Neg}$ & $\mathrm{Neg}$ & Pos & Pos & $<20$ & & \\
\hline 7 & 72 & Female & Pos & Neg & Neg & Pos & Pos & $40,500.0$ & & \\
\hline 8 & 56 & Female & Pos & Neg & $\mathrm{Neg}$ & Pos & Pos & 40.6 & & Yes \\
\hline 9 & 57 & Male & Pos & NA & NA & NA & NA & NA & & \\
\hline 10 & 39 & Male & Pos & NA & NA & NA & NA & 657.0 & & \\
\hline 11 & 50 & Female & Pos & Neg & $\mathrm{Neg}$ & Pos & Pos & 2180.0 & & \\
\hline 12 & 49 & Male & Pos & Neg & $\mathrm{Neg}$ & Pos & Pos & 89.0 & & \\
\hline 13 & 59 & Male & Pos & Neg & $\mathrm{Neg}$ & Pos & Pos & $<20$ & & \\
\hline 14 & 77 & Male & Pos & Neg & $\mathrm{Neg}$ & Pos & Pos & 166.0 & Yes & Yes \\
\hline 15 & 28 & Female & Pos & $\mathrm{Neg}$ & Pos & $\mathrm{Neg}$ & Pos & 1340.0 & & \\
\hline
\end{tabular}

Bold indicates the value of $\mathrm{HBV}-\mathrm{DNA}>20 \mathrm{IU} / \mathrm{mL}$ and is considered as positive

NA Data not available, Pos positive; Neg negative 
developed to the severe situation while the percentage of severe cases was much lower $(24.1 \%)$ in the COVID-19 patients without HBV infection. Two of seven severe HBV and SARS-CoV-2 coinfection patients had cirrhosis whereas the percentage was one out of 26 in the cases of severe COVID-19 without HBV infection.

In the enrolled cases, we also discovered that there was a higher incidence of abnormal liver function (27/33, 81.8\%) in severe COVID-19 patients than did in mild cases $(43.3 \%, 39 / 90$, data not shown), which agrees with the study that lower incidence of AST abnormality was found in the cases diagnosed by CT scan on the subclinical stage than in the COVID-19 patients who were confirmed after onset of symptom (Shi et al. 2020). Therefore, liver function could be considered as one factor to indicate the progress of COVID-19.

In our research, $21.8 \%$ of (7/33) COVID-19 severe patients were found to coinfect with HBV infection. It has been suggested that liver impairment in COVID-19 patients could be due to the direct attack of the virus or resulted by other causes such as drug toxicity and systemic inflammation (Zhang et al. 2020). Detecting the viral RNA or viral particles from liver biopsies of COVID-19 patients will be helpful to elucidate if virus can infect liver tissue. Our results pointed out that as high as $47 \%(7 / 15)$ of $\mathrm{HBV}$ patients were identified as severe COVID-19 cases. It is more likely that HBV patients would suffer from more severe situation during the disease progress when they were encountered with SARS-CoV-2 infection. In our enrolled cases, two patients with SARS-CoV-2 and HBV coinfection died on admission. One patient died from severe liver disease, haptic sclerosis. And the other died from intestinal hemorrhage, which seems to be associated with the impairment of gastrointestinal tract. More coinfection case analyses are required to further understand whether SARSCoV-2 infection aggregates the progress of pre-existing disease and thereby cause death.

Acknowledgements This study was funded by the Zhongnan Hospital of Wuhan University Science, Technology and Innovation Seed Fund (Grant No. znpy2018007). The funders had no role in study design, data collection or analysis, decision to publish or preparation of the manuscript. The authors declared no competing interests.

\section{Compliance with Ethical Standards}

Conflict of interest The authors declare that they have no conflict of interest.

Animal and Human Rights Statement This study was approved by the ethics board in Zhongnan Hospital of Wuhan University, Wuhan, China (No. 2020011). Informed consents were obtained from all patients upon admission to the Department of Infectious Diseases, Zhongnan Hospital of Wuhan University.

\section{References}

Chen N, Zhou M, Dong X, Qu J, Gong F, Han Y, Qiu Y, Wang J, Liu Y, Wei Y, Xia J, Yu T, Zhang X, Zhang L (2020) Epidemiological and clinical characteristics of 99 cases of 2019 novel coronavirus pneumonia in Wuhan, China: a descriptive study. Lancet 395:507-513

Fan Z, Chen L, Li J, Cheng X, Yang J, Tian C, Zhang Y, Huang S, Liu Z, Cheng J (2020) Clinical features of COVID-19-related liver functional abnormality. Clin Gastroenterol Hepatol 18:1561-1566

Guan WJ, Ni ZY, Hu Y, Liang WH, Ou CQ, He JX, Liu L, Shan H, Lei CL, Hui DSC, Du B, Li LJ, Zeng G, Yuen KY, Chen RC, Tang CL, Wang T, Chen PY, Xiang J, Li SY, Wang JL, Liang ZJ, Peng YX, Wei L, Liu Y, Hu YH, Peng P, Wang JM, Liu JY, Chen Z, Li G, Zheng ZJ, Qiu SQ, Luo J, Ye CJ, Zhu SY, Zhong NS, China Medical Treatment Expert Group for C (2020) Clinical characteristics of coronavirus disease 2019 in China. N Engl J Med 382:1708-1720

Huang C, Wang Y, Li X, Ren L, Zhao J, Hu Y, Zhang L, Fan G, Xu J, Gu X, Cheng Z, Yu T, Xia J, Wei Y, Wu W, Xie X, Yin W, Li H, Liu M, Xiao Y, Gao H, Guo L, Xie J, Wang G, Jiang R, Gao Z, Jin Q, Wang J, Cao B (2020) Clinical features of patients infected with 2019 novel coronavirus in Wuhan, China. Lancet 395:497-506

Li Q, Guan X, Wu P, Wang X, Zhou L, Tong Y, Ren R, Leung KSM, Lau EHY, Wong JY, Xing X, Xiang N, Wu Y, Li C, Chen Q, Li D, Liu T, Zhao J, Li M, Tu W, Chen C, Jin L, Yang R, Wang Q, Zhou S, Wang R, Liu H, Luo Y, Liu Y, Shao G, Li H, Tao Z, Yang Y, Deng Z, Liu B, Ma Z, Zhang Y, Shi G, Lam TTY, Wu JTK, Gao GF, Cowling BJ, Yang B, Leung GM, Feng Z (2020) Early transmission dynamics in Wuhan, China, of novel coronavirus-infected pneumonia. N Engl J Med. https://doi.org/ 10.1056/NEJMoa2001316

Liang XF, Bi SL, Yang WZ, Wang LD, Cui G, Cui FQ, Zhang Y, Liu JH, Gong XH, Chen YS, Wang FZ, Zheng H, Wang F, Guo J, Jia ZY, Ma JC, Wang HQ, Luo HM, Li L, Jin SG, Hadler SC, Wang Y (2009) Epidemiological serosurvey of hepatitis B in Chinadeclining HBV prevalence due to hepatitis B vaccination. Vaccine 27:6550-6557

Polaris Observatory C (2018) Global prevalence, treatment, and prevention of hepatitis B virus infection in 2016: a modelling study. Lancet Gastroenterol Hepatol 3:383-403

Shi H, Han X, Jiang N, Cao Y, Alwalid O, Gu J, Fan Y, Zheng C (2020) Radiological findings from 81 patients with COVID-19 pneumonia in Wuhan, China: a descriptive study. Lancet Infect Dis 20:425-434

Wang D, Hu B, Hu C, Zhu F, Liu X, Zhang J, Wang B, Xiang H, Cheng Z, Xiong Y, Zhao Y, Li Y, Wang X, Peng Z (2020) Clinical characteristics of 138 hospitalized patients with 2019 novel coronavirus-infected pneumonia in Wuhan, China. JAMA 323:1061-1069

Xu XW, Wu XX, Jiang XG, Xu KJ, Ying LJ, Ma CL, Li SB, Wang HY, Zhang S, Gao HN, Sheng JF, Cai HL, Qiu YQ, Li LJ (2020) Clinical findings in a group of patients infected with the 2019 novel coronavirus (SARS-Cov-2) outside of Wuhan, China: retrospective case series. BMJ 368:m606

Yang X, Yu Y, Xu J, Shu H, Xia J, Liu H, Wu Y, Zhang L, Yu Z, Fang M, Yu T, Wang Y, Pan S, Zou X, Yuan S, Shang Y (2020) Clinical course and outcomes of critically ill patients with SARSCoV-2 pneumonia in Wuhan, China: a single-centered, retrospective, observational study. Lancet Respir Med 8:475-481

Zhang C, Shi L, Wang FS (2020) Liver injury in COVID-19: management and challenges. Lancet Gastroenterol Hepatol 5:428-430 